\title{
Mechanical analysis of pinning points in the Ross Ice Shelf, Antarctica
}

\author{
Holly STILL ๑, Adam CAMPBELL ๑, Christina HULBE ๑ \\ National School of Surveying, University of Otago, Dunedin, New Zealand \\ E-mail: holly.still@otago.ac.nz
}

\begin{abstract}
Ice shelves regulate the rate of ice-sheet discharge along much of the Antarctic coastline. Pinning points, sites of localised grounding within floating ice, can in turn, regulate the flow and thickness of an ice shelf. While the net resistive effect of ice shelves has been quantified in a systematic way, few extant pinning points have been examined in detail. Here, complete force budgets are calculated and examined for ice rises and rumples in the Ross Ice Shelf, West Antarctica. The diverse features have different effects on ice shelf mechanics that do not depend simply on their size but may, we conclude, depend on the properties of seafloor materials.
\end{abstract}

KEYWORDS: Antarctic glaciology, ice rise, ice shelves

\section{INTRODUCTION}

The floating ice shelves surrounding much of the Antarctic coastline limit mass flux from the interior of the continent (Thomas, 1979; Dupont and Alley, 2006). As a result, changes in ice shelf geometry and dynamics can cause changes in the mass of grounded ice. Ice shelf attributes such as thickness, flow and grounding line position depend in part on the budget of forces in the floating ice. The force budget, in turn, depends on resistive forces originating in lateral drag along embayment walls and areas of localised grounding on elevated seabed topography, called pinning points (Matsuoka and others, 2015).

Pinning points provide resistance to ice shelf flow by modifying the balance of forces within the floating ice. Each pinning point and the grounded ice above it forms, in effect, an obstacle to ice shelf flow. The obstacle generates a reaction force that acts upstream, in opposition to the gravitational driving stress that compels the ice to flow. Because the balance of forces in floating ice is non-local, this reaction force has an effect everywhere in the ice shelf. Of particular interest with respect to ice-sheet stability, pinning points may affect the dynamics of the grounding zone and tributary glaciers, potentially decreasing mass flux in comparison with unrestrained flow (Goldberg and others, 2009; Favier and others, 2012; Fried and others, 2014; Favier and Pattyn, 2015). The magnitude and significance of the dynamic effect appears to depend on the sizes and locations of pinning points (Matsuoka and others, 2015) although this has not been examined in detail.

As localised grounding modifies the balance of forces, further mechanical effects arise. Compression upstream of a pinning point generates thickening, which itself modifies the force balance and may cause additional grounding (Fried and others, 2014). Shear along the margins of a pinning point resists ice shelf flow but shearing may also generate crevasses, rifts and other mechanical effects such as the development of a crystal preferred orientation (MacAyeal and others, 1998; Hulbe and Fahnestock, 2007; Hudleston, 2015). Over time, this may reduce the resistive effect of a pinning point. Downstream of a pinning point, extension together with a redirection of mass flux causes the ice to be thinner than it would otherwise be. Indeed, the non-local nature of the momentum balance in floating ice means that any local change in ice thickness must have shelf-wide consequences as explored, for example, by Campbell and others (2018) and Reese and others (2018). All together, these effects may modify the spatial pattern of a pinning point's influence on the overall force budget over time.

Pinning points can be classified according to their geometry. Ice rises have a distinct dome-shaped topography associated with stagnant or very slow ice motion over a frozen base. Ice shelf flow diverges around the topographic rise and ice rises are often elongated in the direction of ice flow. Ice rumples have more irregular shapes and are relatively small compared with ice rises, rising $<100 \mathrm{~m}$ above the ice shelf surface. The ice in a rumple is in contact with the sea floor and continues to flow directly over the grounded area. Despite their relatively small size, ice rumples still play an important role in determining the balance of forces within an ice shelf (e.g., Berger and others, 2016).

Ice rises and rumples are common features of the Ross Ice Shelf (RIS), Antarctica's largest ice shelf. Large ice rises include Crary Ice Rise (CIR), Roosevelt Island (RI) and Steershead Ice Rise (SIR) (Fig. 1). Many smaller, unnamed ice rumples are located in the eastern sector of the RIS, near the Shirase and Siple Coasts. With the exception of RI, ice rises and rumples are largely absent across the calving front and in the central and western regions of the RIS. The majority of the RIS pinning points are distributed downstream from the large, fast-flowing Siple Coast ice streams that form the main pathway for ice flowing from the interior of the West Antarctic Ice Sheet (WAIS) to the RIS.

Since the Last Glacial Maximum, the grounding zone of the WAIS/RIS has retreated $\sim 1300 \mathrm{~km}$ inland from the continental shelf edge (Conway and others, 1999). Continental shelf morphology has mediated the RIS's prolonged history of retreat (Anderson and others, 2014; Matsuoka and others, 2015). Although the RIS is relatively stable (Pritchard and others, 2012; Campbell and others, 2018), model simulations project a pattern of greater basal melt rates in the eastern sector of the RIS generated by the inflow of water masses from the east (Schodlok and others, 


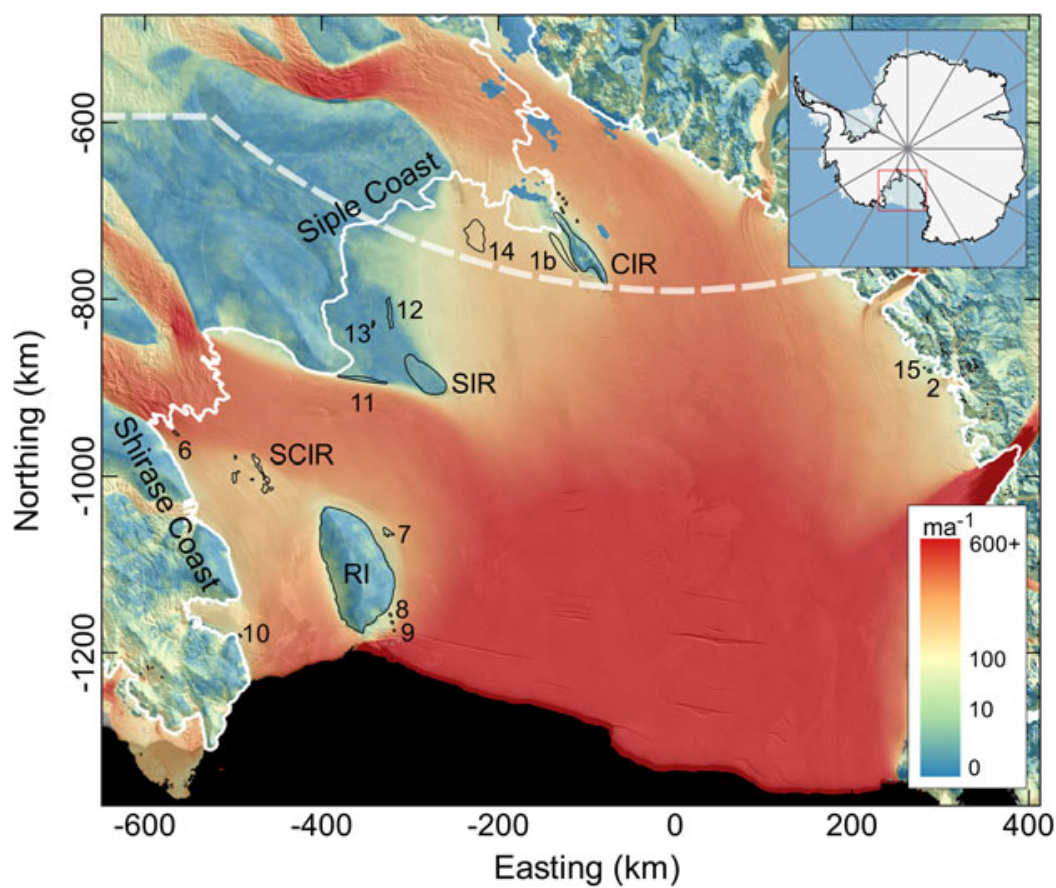

Fig. 1. Pinning points within the Ross Ice Shelf. Larger pinning points are labelled: $S C I R=$ Shirase Coast Ice Rumples, $R I=R o o s e v e l t ~ I s l a n d$, $\mathrm{CIR}=$ Crary Ice Rise, SIR = Steershead Ice Rise. The colour map of velocity magnitude is a synthesis of the Landsat 8 and MEaSUREs velocity data overlayed onto the MODIS MOA (Haran and others, 2014). The white line represents the grounding zone (Bindschadler and others, 2011).

2016). Basal melting can result in both grounding line retreat and detachment from pinning points. With this unpinning, the balance of forces across the whole ice shelf will change, and as a result, ice flow speed and thickness will change as well. Pinning points will continue to mediate the response of the RIS to climate change, albeit with different configurations than at present.

Here, we quantify the mechanical effects of pinning points in the RIS as they appear today using a force budget approach (MacAyeal and others, 1987). This approach partitions drag exerted on the ice shelf into components arising from different processes. The magnitude of the net effective resistance we calculate using these components is analogous to Fürst and others (2016) maximum buttressing number. First, we present a detailed mechanical inventory of the RIS pinning points. Second, the resistive forces exerted by the RIS pinning points on surrounding ice shelf flow are quantified. Several pinning points are examined in detail with the aim of elucidating the full range of effects that pinning points may have on ice shelf behaviour.

\section{RIS PINNING POINTS}

Fifteen pinning points and pinning point complexes are considered here. The coastlines of the associated ice rumples and rises were digitised from the MODIS Mosaic of Antarctica (MOA; Haran and others, 2014) and individual Landsat 8 panchromatic band images. The resolution of the imagery is 250 and $15 \mathrm{~m}$, respectively. Where ice rumple perimeters were indistinct, changes in ice surface elevation associated with localised grounding were identified in the Geoscience Laser Altimeter System (GLAS) 500 m DEM of Antarctica (DiMarzio, 2007). The traces of some ice rumple perimeters differ in detail from those inventoried by Matsuoka and others (2015) and one additional feature, a very small ice rumple $\left(3 \mathrm{~km}^{2}\right)$ nearby Deverall Island (\#2), is included (ice rumple \#15) (Fig. 1).

The persistence of each pinning point can be inferred from downstream flow features in the ice shelf such as crevasses and streaklines (Fahnestock and others, 2000). Streaklines stretching downstream from CIR and the Shirase Coast Ice Rumples (SCIR) extend to the ice shelf front indicating that these pinning points are long-lived features, persisting for hundreds of years. The crevasse track originating from SIR does not extend to the ice shelf front and it can be inferred that the ice rise became well-grounded 350-400 years ago (Fahnestock and others, 2000). Traces downstream of the small pinning points offshore from RI are visible only a few kilometres downstream, indicating formation within the last 100-200 years although snow cover may obscure part of the record. Where they are long-lived, changes in streakline character may reveal changes in pinning point morphology and degree of grounding over time. A streakline originating from the easternmost edge of the SCIR is wider and more undulating further downstream than closer to the ice rumples, suggesting a greater degree of grounding or a larger feature between 400 and 700 years ago. Smaller rumples or lightly grounded features do not generate crevasse patterns or streaklines that are detectable in satellite images and their persistence over time is more difficult to investigate.

\section{DATA}

\section{Velocity and strain rate}

Strain rates derived from observed ice shelf flow are used in the ice mechanics analysis. Here, components of the infinitesimal strain rate tensor $\dot{\epsilon}_{i j}$ are calculated as spatial gradients in the surface velocity field

$$
\dot{\epsilon}_{i j}=\frac{1}{2}\left[\frac{\partial u_{i}}{\partial x_{j}}+\frac{\partial u_{j}}{\partial x_{i}}\right]
$$


where the subscripts $i$ and $j$ represent the horizontal directions $x$ and $y$, and $u$ represents the flow velocity with components $u_{x}$ and $u_{y}$.

Two different velocity datasets are used in the present work. North of $82.5^{\circ} \mathrm{S}$, strain rates are calculated from the Landsat 8-derived flow velocity dataset (K. Alley, pers. comm., 2016, Fahnestock and others, 2016). The resolution is $750 \mathrm{~m}$ and errors on individual velocities vary from 5 to 10 $\mathrm{ma}^{-1}$. This dataset represents the time interval between 2013 and 2016 when the images were acquired. South of the Landsat 8 limit, we use the MEaSUREs velocity dataset, available at 450 and $900 \mathrm{~m}$ resolution (Rignot and others, 2011a). The 900 m resolution product, which has data gaps but lacks some of the artefacts present in the $450 \mathrm{~m}$ resolution product is used in the ice mechanics analysis to minimise artefacts in the strain rate calculation. This velocity product was assembled from multiple interferometric synthetic aperture radar datasets acquired between 2007 and 2009 with errors varying from 3 to $5 \mathrm{ma}^{-1}$ over the RIS (Rignot and others, 2011b). Errors on strain rates computed directly from the gridded velocity would be very large, of the order of $0.01 \mathrm{a}^{-1}$. Thus, strain rates are averaged over several grid cells to reduce noise, as discussed further in the Application section.

\section{Ice shelf thickness}

Ice shelf thickness may be inferred from surface elevation (freeboard) by assuming that the ice is floating in hydrostatic equilibrium (e.g., Griggs and Bamber, 2009; Le Brocq and others, 2010). The thickness $H$ is calculated

$$
H=\frac{(s-f) \rho_{\mathrm{w}}}{\rho_{\mathrm{w}}-\rho_{\mathrm{i}}}+f
$$

where $s$ is the surface elevation above mean sea level, $\rho_{\mathrm{w}}$ is the density of ocean water $\left(1028 \mathrm{~kg} \mathrm{~m}^{-3}\right)$ and $\rho_{\mathrm{i}}$ is the density of ice $\left(917 \mathrm{~kg} \mathrm{~m}^{-3}\right)$. Where ice runs aground, the difference between the surface elevation and the Bedmap2 bed elevation is computed. The firn density correction $f$ reduces $H$ to the ice shelf thickness when the firn layer is compacted to $\rho_{\mathrm{i}} . f$ on the RIS varies between 16 and $19 \mathrm{~m}$ (van den Broeke and others, 2008). $s$ is obtained from the GLAS 500 $m$ DEM of Antarctica (DiMarzio, 2007). This DEM was created from repeat observations of surface elevation acquired between February 2003 and June 2005.

Each measured value in Eqn (2) introduces error into the final ice shelf thickness map. The firn correction has a reported uncertainty of $4 \mathrm{~m}$ along the RIS grounding line (van den Broeke and others, 2008). The original authors of the GLAS $500 \mathrm{~m}$ DEM do not report its uncertainty, though a related analysis on the Amery Ice Shelf uses $0.08 \pm 0.82 \mathrm{~m}$ for the mean and standard error (Wen and others, 2010). In view of this, a conservative estimate of the uncertainty in surface elevation, $1 \mathrm{~m}$, is used here, although the actual uncertainty for the RIS is probably much smaller due to its low surface slope. Uncertainties associated with each component are added in quadrature (Taylor, 1997, p. 75). All together, the uncertainty in $H$ is $34.3 \mathrm{~m}(1 \sigma)$. In comparison, the Bedmap2 ice thickness has a reported error of $150 \mathrm{~m}$ for the RIS (Fretwell and others, 2013). Uncertainty in $H$ is used later to assess the uncertainty in the force budget components.

The thickness of ice above buoyancy $H_{a b}$ indicates the degree of groundedness of a pinning point. When $H_{a b}$ is larger, tides are less likely to affect the ice and more thinning (or sea-level rise) is required to lose contact with the sea floor. For reference, the tidal amplitude in the RIS cavity is $< \pm 1 \mathrm{~m}$ (Padman and others, 2003). The calculation

$$
H_{a b}=(H-f)+\left(\rho_{\mathrm{w}} / \rho_{\mathrm{i}}\right) b
$$

requires bed elevation $b$ but this is not well resolved beneath the smallest ice rumples. $b$ is obtained from the Bedmap2 bed elevation dataset (Fretwell and others, 2013).

\section{Inverse rate factor}

The depth-averaged flow law inverse rate factor $\bar{B}$ is used to convert strain rates into stresses. It is expected to vary across the ice shelf as a function of ice temperature and perhaps other ice material properties (Cuffey and Paterson, 2010, p. 64-72). $\bar{B}$ can be inferred from other quantities in the force budget calculations but without explicit knowledge of ice temperature, cannot be independently calculated. Observed depth-averaged temperature profiles for the RIS indicate that a $\bar{B}$ value of $1.6 \times 10^{8} \mathrm{~Pa} \mathrm{~s}^{1 / 3}$ is appropriate. Depth-averaged temperatures for the 19 borehole nearby CIR (Clough and Hansen, 1978; MacAyeal and others, 1987; Engelhardt, 2004) and the Little America borehole nearby RI (Crary, 1961) are $-16.31^{\circ} \mathrm{C}$ and $-17.11^{\circ} \mathrm{C}$, respectively. These temperatures correspond to a $\bar{B}$ range of $1.57 \times 10^{8}$ to $1.63 \times 10^{8} \mathrm{~Pa} \mathrm{~s}^{1 / 3}$ (Cuffey and Paterson, 2010, p. 75). In addition, Jezek and others (1985) calculated the average rate factor $A$ for the RIS from strain rate measurements and inferred values of the backstress $\sigma_{b}$. They determined $A=2.3 \times 10^{-25} \mathrm{~Pa}^{-3} \mathrm{~s}^{-1}$, which corresponds to a $\bar{B}$ of $1.63 \times 10^{8} \mathrm{~Pa} \mathrm{~s}^{1 / 3}$.

Uncertainty in $\bar{B}$ also arises from regional variations in ice temperature and material properties and therefore is difficult to quantify. From the existing borehole temperature measurements, we use $\pm 2{ }^{\circ} \mathrm{C}$ as a conservative estimate of the variation in depth-averaged ice temperature. Varying a depth-averaged temperature of $-16.7^{\circ} \mathrm{C}$ by $\pm 2^{\circ} \mathrm{C}$ gives a $\bar{B}$ uncertainty range of $1.49 \times 10^{8}$ to $1.72 \times 10^{8} \mathrm{~Pa} \mathrm{~s}^{1 / 3}$. Applying this uncertainty in the error propagation thus accounts for the application of a uniform $\bar{B}$ in the conversion of strain rates into stresses.

\section{FORCE BUDGETS OF PINNING POINTS}

The effective resistance generated by each of the RIS pinning points can be quantified using a local force budget calculation (MacAyeal and others, 1987). In this approach, the net traction vector acting on an imaginary contour $\Gamma$ surrounding the pinning point and its associated grounded ice is partitioned into form drag and dynamic drag components estimated from observed quantities. Form drag is due to the size and shape of the obstacle within the flow field. Dynamic drag is due to the viscous deformation of the ice around the obstacle. While other approaches have been used to generate an all-encompassing buttressing parameter (Borstad and others, 2013; Gudmundsson, 2013; Fürst and others, 2016), our method calculates individual form drag and dynamic drag components and resolves the directional effects of the flow resistance generated by pinning points.

Form drag $\mathbf{F}_{f}$ is the glaciostatic contribution to the net resistance. Ice rises and rumples that are relatively streamlined in the flow direction generate less disturbance to the 
thickness field and less $\mathbf{F}_{\mathrm{f}}$ than pinning points that are oriented transverse to flow. When the thickness of the ice shelf is uniform, $\mathbf{F}_{f}$ is zero. $\mathbf{F}_{f}$ is calculated by dividing the contour $\Gamma$ around an ice rise or rumple into length elements $\mathrm{d} \lambda$ with normals $\hat{\mathbf{n}}$

$$
\mathbf{F}_{\mathrm{f}}=\oint_{\Gamma}\left\{\frac{1}{2} \rho_{i} g H^{2}+\frac{\alpha}{\beta} g H+\frac{\alpha}{\beta^{2}}\left(1-e^{\beta H}\right) g\right\} \hat{\mathbf{n}} \mathrm{d} \lambda
$$

where $g$ is acceleration due to gravity $\left(9.81 \mathrm{~ms}^{-2}\right)$. The second and third terms account for the lower density of the firn layer using the constants $\alpha$ and $\beta$ from the usual depthdensity relation (Cuffey and Paterson, 2010, p.19)

$$
\rho(z)=\rho_{\mathrm{i}}-\alpha \exp \left(\beta\left(z_{\mathrm{s}}-z\right)\right)
$$

where $\rho(z)$ is the density at depth $z, z_{\mathrm{S}}$ is the $z$-coordinate of the ice-shelf surface, and $\rho_{\mathrm{i}}$ is the density of ice at the surface. $\alpha$ and $\beta$ vary across the ice shelf and cannot be calculated without prior in situ measurements of the firn density profile. Values of $\alpha=608 \mathrm{~kg} \mathrm{~m}^{-3}$ and $\beta=-0.043 \mathrm{~m}^{-1}$ are used here (MacAyeal and others, 1987).

Dynamic drag $\mathbf{F}_{\mathrm{d}}$ is the viscous resistance associated with ice deformation around an ice rise or rumple. $\mathbf{F}_{\mathrm{d}}$ reaches a maximum when ice velocity around a pinning point reduces to zero. It is calculated around the contour surrounding the obstacle

$$
\mathbf{F}_{\mathrm{d}}=-\oint_{\Gamma} 2 \bar{v}^{Z} H\left\{\dot{\boldsymbol{\epsilon}}_{i j} \cdot \hat{\mathbf{n}}+\left(\dot{\boldsymbol{\epsilon}}_{x x}+\dot{\boldsymbol{\epsilon}}_{y y}\right) \hat{\mathbf{n}}\right\} \mathrm{d} \lambda
$$

where $\bar{v}^{z}$ is the effective depth-averaged viscosity and $\dot{\epsilon}_{i j}$ is the strain rate tensor. The effective viscosity parameter $\bar{v}^{z}$ is

$$
\bar{v}^{z}=\frac{\bar{B}}{2 \dot{\epsilon}_{e}^{1-1 / n}}
$$

where $\bar{B}$ is the depth-average, inverse flow-law rate constant and $n=3$ is the flow-law exponent. The effective strain rate $\dot{\epsilon}_{e}$ is the second invariant of the strain rate tensor

$$
\dot{\epsilon}_{\mathrm{e}}^{2}=\frac{1}{2}\left(\dot{\epsilon}_{x x}^{2}+\dot{\epsilon}_{y y}^{2}+\dot{\epsilon}_{z z}^{2}\right)+\dot{\epsilon}_{x y}^{2}+\dot{\epsilon}_{x z}^{2}+\dot{\epsilon}_{y z}^{2}
$$

The local significance of $\mathbf{F}_{\mathrm{f}}$ and $\mathbf{F}_{\mathrm{d}}$ can be assessed by calculating the imaginary resistive force that would exist at the same location on the ice shelf, but in the absence of the pinning point. In this situation, the region contained within the contour $\Gamma$ consists only of floating ice shelf with the pinning point replaced by seawater. The force transmitted through $\Gamma$ is the seawater pressure $\mathbf{F}_{\mathrm{w}}$

$$
\mathbf{F}_{\mathrm{w}}=\oint_{\Gamma} \frac{1}{2} \frac{g}{\rho_{w}}\left\{\rho_{i} H+\frac{\alpha}{\beta}\left(1-\mathrm{e}^{\beta H}\right)\right\}^{2} \hat{\mathbf{n}} \mathrm{d} \lambda .
$$

The difference between $\left(\mathbf{F}_{\mathrm{f}}+\mathbf{F}_{\mathrm{d}}\right)$ and $\mathbf{F}_{\mathrm{w}}$ is the effective resistance $\mathbf{F}_{\mathrm{e}}$, the total reaction force arising from contact between the pinning point and the base of the ice shelf

$$
\mathbf{F}_{\mathrm{e}}=\mathbf{F}_{\mathrm{f}}+\mathbf{F}_{\mathrm{d}}-\mathbf{F}_{\mathrm{w}}
$$

For an area of floating ice shelf free of ice rises or rumples, $\mathbf{F}_{\mathrm{e}}$ should equal zero or fall within the uncertainty range of zero given the satellite-derived data available for this calculation. When the magnitude of $\mathbf{F}_{\mathrm{e}}$ for an ice rumple is within the uncertainty of zero, the feature cannot be claimed to make a contribution to flow resistance.

Uncertainty in the force budget calculation arises from (1) the errors in the velocity data and strain rates calculated from velocity gradients; (2) error in the GLAS 500 m DEM and inferred ice shelf thickness; and (3) the estimated $\bar{B}$ value (Table 1). Uncertainty in derived quantities is evaluated by adding the individual sources of error in quadrature (Taylor, 1997, p. 75).

\section{Application}

The force budget analysis is applied to the RIS ice rises and rumples listed in Table 2 . Ice rumples nearby one another (e.g., the SCIR complex, CIR and its offshore rumple \#1b) are treated as a single feature contained by a single closed contour $\Gamma$. Terms in the force budget are calculated along circular or elliptical shaped contours composed of numerous smaller segments. Each contour encloses the surface features, small areas of floating ice shelf surrounding the pinning point, and any regions of crevassing originating from the ice rise or rumple. The contour boundary can be imagined as a vertical cylinder intersecting the ice shelf. The number of segments comprising each contour is scaled to the size of the ice rise or rumple.

Ice thickness and strain rate components must be interpolated from the gridded datasets to the polygon vertices. Two methods were tried and compared. The first method applied linear interpolation to return strain rate and thickness at each vertex. In the second method, average values were calculated within a fixed radius around each vertex. The averaging radius is varied according to the nearness of the pinning point to other grounded features. The second method was preferred because spatial averaging reduces noise in the input datasets and consequently the propagated errors in $\mathbf{F}_{\mathrm{f}}$ and $\mathbf{F}_{\mathrm{d}}$ are smaller. The same averaging method is applied to the ice shelf thickness data for consistency. Force budget components (Eqns $(4,6,9))$ are determined from the gridded ice thickness and strain rate data (integrals are computed in the Appendix).

When the ice runs aground to form an ice rumple, a traction arises on the plane between the two materials and this is related to the effective resistance. The apparent basal shear stress $\tau_{\mathrm{b}}$ is computed as the quotient of $\mathbf{F}_{\mathrm{e}}$ and the pinning point area. The contact area is not observable so it is approximated as the surface area of the ice rumple.

\section{RESULTS}

\section{Inventory of RIS pinning points}

The flow-modifying effects of the RIS pinning points span two orders of magnitude in $\mathbf{F}_{\mathrm{e}}$ (Fig. 2, Table 2). In general, large

Table 1. Uncertainties of variables in the force budget calculations

\begin{tabular}{ll}
\hline Variable & Uncertainty \\
\hline Flow speed (L8) & $5-10 \mathrm{ma}^{-1}$ \\
Flow speed (MEaSUREs) & $3-5 \mathrm{ma}^{-1}$ \\
Strain rate & $\left(\sigma_{v}^{2}+\sigma_{v}^{2}\right) / \Delta x^{2}$ \\
Surface elevation (GLAS) & $1 \mathrm{~m}$ \\
Firn correction & $4 \mathrm{~m}$ \\
Ice thickness & $34.3 \mathrm{~m}$ \\
Rate factor & $15 \%$ of $\bar{B}$ \\
&
\end{tabular}


Table 2. Mechanical inventory of pinning points in the RIS. $1=$ Crary Ice Rise, $2=$ Deverall Island, $3=$ Roosevelt Island and $4=$ Steershead Ice Rise. Pinning points 5-15 are ice rumples

\begin{tabular}{|c|c|c|c|c|c|c|c|c|c|c|}
\hline ID & $\begin{array}{l}\text { Length } \\
(\mathrm{km})\end{array}$ & $\begin{array}{l}\text { Area } \\
\left(\mathrm{km}^{2}\right)\end{array}$ & $\left(\mathrm{ma}^{-1}\right)$ & $\begin{array}{l}\text { Height } \\
\text { (m) }\end{array}$ & $\begin{array}{l}H_{a b} \\
(\mathrm{~m})\end{array}$ & $\begin{array}{c}\mathbf{F}_{\mathrm{f}} \\
\left(\times 10^{12} \mathrm{~N}\right)\end{array}$ & $\begin{array}{c}\mathbf{F}_{\mathrm{d}} \\
\left(\times 10^{12} \mathrm{~N}\right)\end{array}$ & $\mathbf{F}_{\mathrm{d}} / \mathbf{F}_{\mathrm{f}}$ & $\begin{array}{c}\mathbf{F}_{\mathrm{e}} \\
\left(\times 10^{12} \mathrm{~N}\right)\end{array}$ & $\begin{array}{c}\tau_{\mathrm{b}} \\
(\mathrm{kPa})\end{array}$ \\
\hline 1 (CIR) & 100.3 & 1184.8 & 6.5 & 121.0 & 79.0 & $63.0 \pm 2.0$ & $8.0 \pm 0.4$ & 0.13 & $14.6 \pm 2.4$ & $*$ \\
\hline $1 \mathrm{~b}$ & 52.3 & 286.2 & 73.7 & 27.2 & -45.0 & & & & & \\
\hline 2 & 4.2 & 13.1 & 7.0 & 11.7 & $*$ & $3.1 \pm 0.4$ & $0.6 \pm 0.3$ & 0.19 & $0.7 \pm 0.6$ & $*$ \\
\hline $3(\mathrm{RI})$ & 148.2 & 7832.3 & 5.7 & 543.4 & 507.1 & $124.7 \pm 3.2$ & $7.6 \pm 1.8$ & 0.06 & $20.8 \pm 4.8$ & $*$ \\
\hline $4(\mathrm{SIR})$ & 58.2 & 1152.3 & 4.3 & 33.6 & 40.1 & $15.5 \pm 2.1$ & $4.3 \pm 1.6$ & 0.28 & $5.6 \pm 3.1$ & 4.9 \\
\hline 6 & 8.2 & 20.8 & 437.9 & 9.0 & -1.3 & $1.7 \pm 1.0$ & $0.6 \pm 0.4$ & 0.35 & $0.4 \pm 1.3$ & 17.9 \\
\hline 7 & 14.5 & 60.2 & 88.8 & 38.8 & 6.2 & $19.8 \pm 1.4$ & $1.2 \pm 0.5$ & 0.06 & $3.2 \pm 1.9$ & 54.0 \\
\hline 8 & 4.4 & 9.5 & 27.9 & 30.1 & $*$ & $1.3 \pm 0.3$ & $0.4 \pm 0.2$ & 0.31 & $0.4 \pm 0.4$ & 46.8 \\
\hline 9 & 4.0 & 8.6 & 25.1 & 33.8 & * & $2.3 \pm 0.3$ & $0.7 \pm 0.1$ & 0.30 & $0.9 \pm 0.4$ & 102.7 \\
\hline 10 & 4.4 & 7.6 & 105.0 & 6.7 & $*$ & $2.1 \pm 0.3$ & $0.5 \pm 0.3$ & 0.24 & $0.7 \pm 0.6$ & 89.7 \\
\hline 11 & 56.8 & 185.7 & 6.3 & 19.3 & 9.2 & $11.9 \pm 1.7$ & $3.4 \pm 1.3$ & 0.29 & $4.3 \pm 1.7$ & 22.9 \\
\hline 12 & 35.5 & 136.0 & 3.4 & 23.7 & 12.1 & $8.7 \pm 1.6$ & $1.5 \pm 2.0$ & 0.17 & $2.0 \pm 1.8$ & 14.7 \\
\hline 15 & 2.0 & 3.0 & 26.8 & 5.0 & $*$ & $0.8 \pm 0.3$ & $0.3 \pm 0.4$ & 0.38 & $0.3 \pm 0.6$ & 103.0 \\
\hline
\end{tabular}

ice rises (RI, CIR, SIR) generate a larger $\mathbf{F}_{\mathrm{e}}$ than the smallerscale ice rumples. However, the SCIR generate $\mathbf{F}_{\mathrm{e}}$ comparable with the $\mathbf{F}_{\mathrm{e}}$ generated by $\mathrm{RI}$ and $\mathrm{CIR}$, and approximately double the $\mathbf{F}_{\mathrm{e}}$ generated by SIR. In general, $\mathbf{F}_{\mathrm{e}}$ is oriented upstream along the long axis of the ice rise or rumple. CIR and $\mathrm{RI}$ are a notable exception to this. These ice rises and the SCIR are discussed in more detail below.

The relative contributions of $\mathbf{F}_{\mathrm{f}}$ and $\mathbf{F}_{\mathrm{d}}$ to ice flow resistance also vary across the different features (Table 2). For almost all of the pinning points, $\mathbf{F}_{\boldsymbol{f}}$ is the dominant term in the force budget. $\mathbf{F}_{f}$ is associated with relative compression and thickening upstream and relative extension and thinning

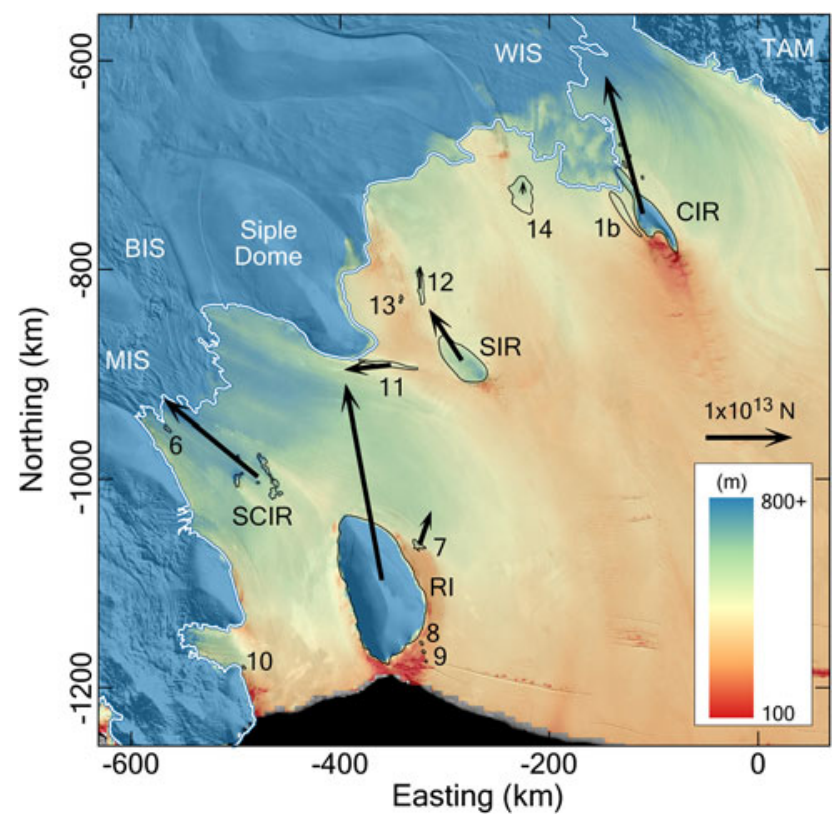

Fig. 2. Ross Ice Shelf thickness and the effective resistance $\mathbf{F}_{\mathrm{e}}$ generated by each pinning point. Ice thickness $(\mathrm{m})$ is computed from the GLAS $500 \mathrm{~m}$ surface elevation model (DiMarzio, 2007) and a firn correction map (Le Brocq and others, 2010), and overlayed onto the MODIS MOA (Haran and others, 2014). The white line represents the grounding zone (Bindschadler and others, 2011). downstream of an obstacle. Unsurprisingly, larger ice rises generate larger $\mathbf{F}_{\mathrm{f}}$, except for SIR. The ratio $\mathbf{F}_{\mathrm{d}}: \mathbf{F}_{\mathrm{f}}$ is larger for ice rumples than for ice rises by approximately one order of magnitude. Using this metric as a criterion, SIR is classified as an ice rumple rather than an ice rise, even though velocity over the grounded area is very low. SIR generates significant disruption to the surrounding ice deformation field and therefore has a larger $\mathbf{F}_{\mathrm{d}}: \mathbf{F}_{\mathrm{f}}$ ratio.

\section{The SCIR}

The SCIR are located approximately halfway between RI and the outlet of MacAyeal Ice Stream (MacIS). The ice rumples have an irregular, undulating topography and are approximately oriented in the direction of ice flow, but are not streamlined. Wakes of heavily crevassed ice extend downstream from the two largest rumples for $\sim 20 \mathrm{~km}$ (Fig. 3a). Several distinct features comprise the rumple complex. The largest has an area of $78 \mathrm{~km}^{2}$ while the smallest has an area of just $4 \mathrm{~km}^{2}$. Collectively, the rumples extend over an area of $240 \mathrm{~km}^{2}\left(1400 \mathrm{~km}^{2}\right.$ inclusive of floating ice between the pinning points). Individual rumples are relatively small features, but all together the rumple complex generates a large $\mathbf{F}_{\mathrm{e}}$ (Fig. 2).

Ice flowing over the pinning points originates from MaclS. Ice speed decreases from $400 \mathrm{ma}^{-1}$ as ice approaches the rumpled region, to $200 \mathrm{ma}^{-1}$ immediately downstream (Fig. 1). The ice rumples support thicker ice upstream $(H=$ $730 \mathrm{~m})$, and thinner ice downstream $(H=520 \mathrm{~m})$ and divert faster ice flow from MaclS around the western shore of RI (Figs 1 and 2). This redirection also increases the ice shelf thickness downstream of Bindschadler Ice Stream (labelled BIS in Fig. 2).

Force budgets for individual ice rumples, which can be inferred from the pattern of $\mathbf{F}_{\mathrm{f}}$ and $\mathbf{F}_{\mathrm{d}}$ vector components around the rumple complex, depend on their position relative to other rumples. $\mathbf{F}_{f}$ magnitudes along the upstream (southeast) edge of the rumples are $30 \%$ higher than $\mathbf{F}_{f}$ along the downstream (northwest) edge (Fig. 4a). The western flank also generates a slightly greater $\mathbf{F}_{\mathrm{f}}$ than the eastern flank, associated with thicker ice to the west and 

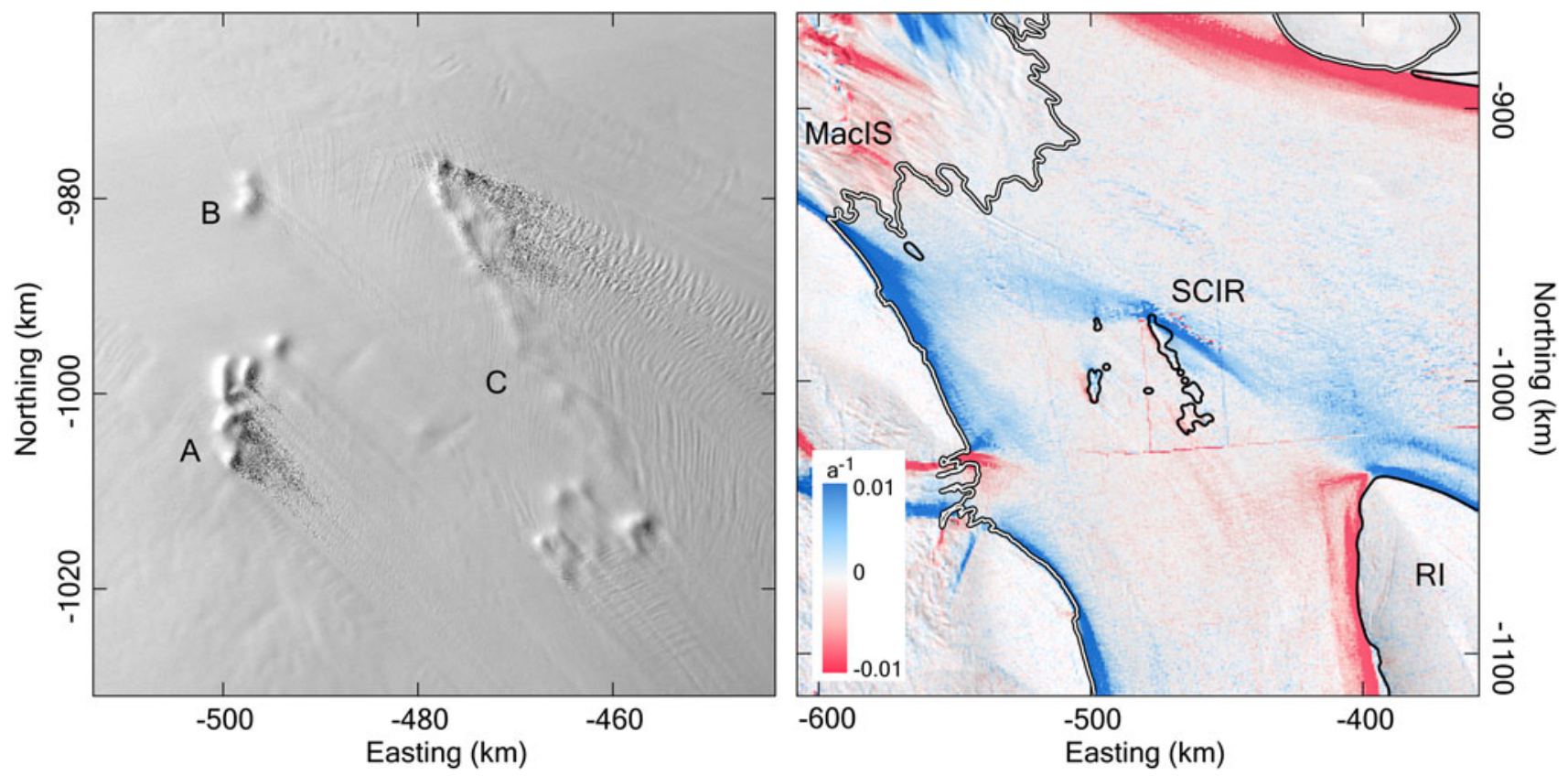

Fig. 3. The SCIR: (a) Surface morphology and crevasse patterns. The panchromatic image is from Landsat 8, Path 021 Row 118 , acquired on 3 February 2016. (b) Shear strain rate in a flow-following coordinate system computed using the Landsat 8 velocity data.

thinner ice in the lee of the upstream-most rumples. Net $\mathbf{F}_{\mathrm{f}}$ is therefore directed upstream (Fig. 4c).

The upstream and southwest flank of the ice rumple complex (labelled B and C in Fig. 3) contributes the largest
$\mathbf{F}_{\mathrm{d}}$ (Fig. 4b). The eastern rumples (labelled $\mathrm{A}$ in Fig. 3) are in the flow shadow of the remaining rumples and thus contribute minimal dynamic drag. Nevertheless, rumple A contributes to the overall force balance by generating a

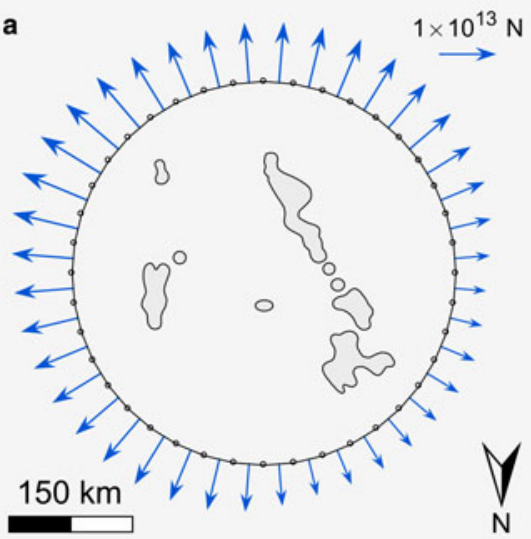

d

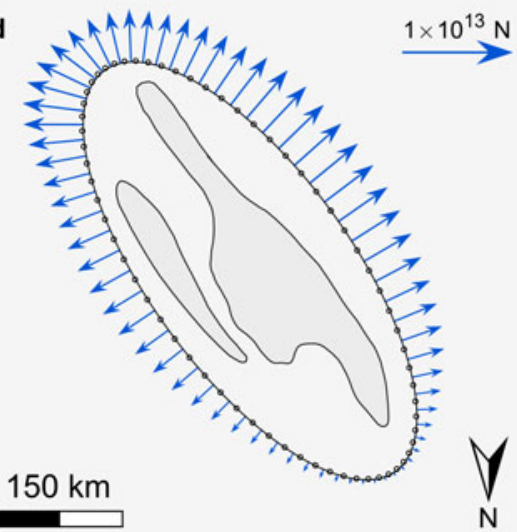

b
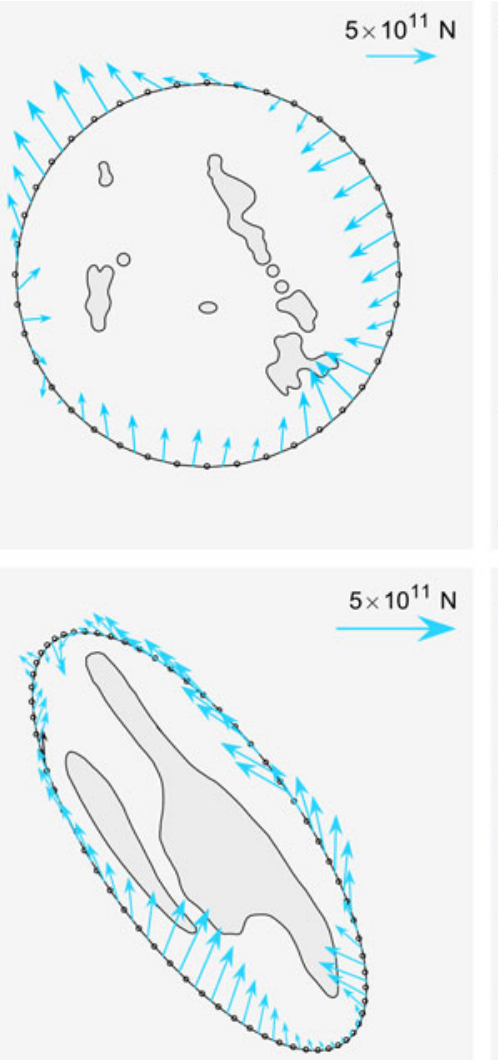
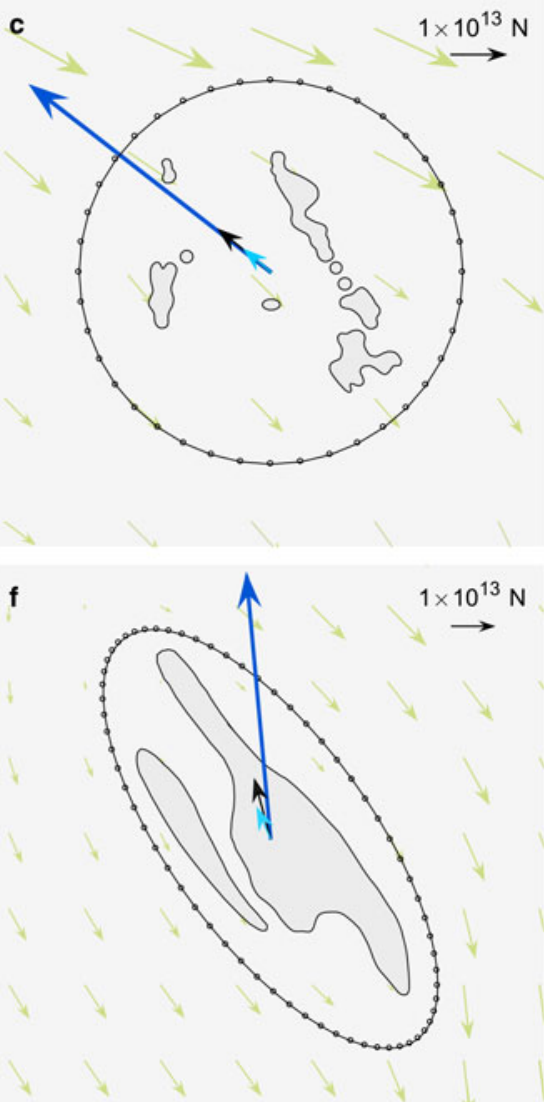

Fig. 4. SCIR and CIR force budget components. Individual $\mathbf{F}_{f}$ vector components are shown in panels (a) and (d). $\mathbf{F}_{d}$ vector components are shown in panels (b) and (e). Panels (c) and (f) show the relative magnitudes of net $\mathbf{F}_{\mathrm{f}}$ (dark blue), net $\mathbf{F}_{\mathrm{d}}$ (light blue) and $\mathbf{F}_{\mathrm{e}}$ (black). Green vectors indicate the flow direction. Force budget vector components in (a), (b), (d) and (e) are scaled differently to demonstrate spatial patterns around the pinning point complexes. 
compressive stresses in the upstream direction. Net $\mathbf{F}_{\mathrm{e}}$ is directed upstream and therefore the flow regulating effect of the ice rumples is mainly on MaclS and its grounding line.

A continuous band of relatively large shear strain rates extends from the Shirase Coast, near the outlet of Macls, to the southernmost shore of RI (Fig. 3b). This band can be seen as both a cause and consequence of the preferred ice flux direction south of the ice rumples, between Siple Dome and the SCIR. The pinning points modify the force budget by creating a band of shearing diverted away from the coast. This, in turn, favours thicker ice and faster flow south of the rumples and continued shearing reinforces this pattern. It also reduces mass flux to the north, resulting in relatively thinner ice between $\mathrm{RI}$ and the coast.

The SCIR have two further effects on the wider RIS. First, thinning downstream of the rumples results in a thickness gradient around $\mathrm{RI}$ that is not oriented along flow. As a result, $\mathrm{RI}^{\prime}$ s force budget is characterised by a relatively large $\mathbf{F}_{\mathrm{e}}$ oriented $40^{\circ}$ against the direction of flow, toward Siple Dome (Fig. 2). Second, ice flow downstream of the BIS grounding line is relatively thick due to MaclS flow diversion around the SCIR, generating larger flow buttressing (Fürst and others, 2016) than would be the case for thinner ice.

\section{CIR}

Unlike the SCIR, CIR is a demonstrably long-lived feature that is unlikely to experience changes in morphology or extent of grounding over the coming decades. The formation of CIR began with ice freezing on the bed at the southern (upstream) end 1100 years ago and the northern end stagnating 500 years later (Bindschadler and others, 1990). Ice stream discharge around the ice rise has been variable since that time (Hulbe and Fahnestock, 2007) and recently, flow across the lightly-grounded ice plain upstream of CIR has slowed (Joughin and others, 2005; Winberry and others, 2014). Ice thickness around CIR has also changed over time as a result of its stagnation and changes in the flux of ice from upstream (Hulbe and others, 2013; Fried and others, 2014).

CIR consists of a prominent dome rising $\sim 100 \mathrm{~m}$ above the ice surface along an $80 \mathrm{~km}$ ridge aligned with the direction of ice flow. The southernmost tip of the CIR ridge intersects the Whillans Ice Stream (WIS) ice plain and ice flow diverges around the grounded feature. Shearing between the stagnant ice of $\mathrm{CIR}$ and the much faster-flowing ice stream and ice shelf creates narrow crevassed margins and a wake of extensive crevassing extending $100 \mathrm{~km}$ downstream. A large ice rumple (\#1b in Fig. 1), off the eastern shore of CIR, is also aligned in the flow direction. Several very small features near the grounding line south of CIR are apparent in the MOA and the GLAS $500 \mathrm{~m}$ DEM. CIR and the large ice rumple are treated as a single feature for the force budget analysis. Of all the pinning points in the RIS, CIR generates the second largest $\mathbf{F}_{\mathrm{e}}\left(14.6 \pm 2.4 \times 10^{12} \mathrm{~N}\right)$.

Several smaller, potential pinning points around CIR appear as changes in surface texture but are not associated with changes in velocity. The larger feature east of CIR (\#1b in Fig. 1) was described by Bindschadler and others (1988) as an 'ice raft', or a block of crevasse free ice with regular internal layers, detached from CIR and moving with the surrounding ice flow. Its most recently measured speed is $73 \mathrm{ma}^{-1}$ (Fig. 1), while Bindschadler and others (1988) reported a speed of $140 \mathrm{ma}^{-1}$. Ice rumple \#1b rises $27 \mathrm{~m}$ above the surrounding ice surface (Table 2) however, the resolution of the Bedmap2 bed elevation is not fine enough to determine whether the ice runs aground at this site.

CIR modifies flow velocity and ice thickness in the region (Figs 1 and 2). Upstream, ice speed decelerates from 300 $\mathrm{ma}^{-1}$ to nearly $0 \mathrm{ma}^{-1}$ over a distance of $70 \mathrm{~km}$. Net $\mathbf{F}_{\mathrm{d}}$ is oriented upstream in the direction of the long axis of the ice rise (Fig. 4f). The RIS is relatively thicker on the western side of CIR because ice flow is constricted between the ice rise and the Transantarctic Mountains. This arrangement influences the alignment of the net $\mathbf{F}_{f}$ vector. Rather than alignment with the flow direction, $\mathbf{F}_{\mathrm{f}}$ and $\mathbf{F}_{\mathrm{e}}$ are aligned $30^{\circ}$ against the direction of ice shelf flow, towards the Transantarctic Mountains (Fig. 2). Through its effect on regional ice thickness, the ice rise thus affects the force budgets of multiple ice stream and glacier grounding lines.

\section{DISCUSSION}

Pinning points modify the force and mass budgets of ice shelves. Where the ice runs aground, a new resistive force is generated and the driving force must become larger to overcome the additional resistive force. Thickening upstream generates the additional driving force. Expressed another way, strain rates are modified where the ice runs aground, with relative compression upstream, shear along the margins of the obstacle and extension downstream. The resulting change in ice flux generates thickening upstream and thinning downstream of the pinning point. The net effects are captured in our calculation of $\mathbf{F}_{\mathrm{f}}$ and $\mathbf{F}_{\mathrm{d}}$.

The ratio $\mathbf{F}_{\mathrm{d}}: \mathbf{F}_{\mathrm{f}}$ indicates the relative importance of the resistive forces generated by individual features. The SCIR, CIR, RI and the unnamed ice rumples $\# 7$ and $\# 14$, have similar, relatively small, $\mathbf{F}_{\mathrm{d}}: \mathbf{F}_{\mathrm{f}}$ (Table 2 ). Their influence on the ice thickness field thus appears to be relatively more important to the force budget than for other pinning points. The group of ice rumples downstream of Siple Dome (SIR, $\# 11, \# 12, \# 13$ ) all have relatively high $\mathbf{F}_{\mathrm{d}}: \mathbf{F}_{\mathrm{f}}$. They are located in a region of relatively slow flow, yet they have a relatively larger influence on the velocity field than other pinning points.

The range of $\mathbf{F}_{\mathrm{e}}$ cannot be explained by either pinning point area $A$ or location in the flow field alone (Fig. 5a). For example, the relatively small SCIR are responsible for a relatively large $\mathbf{F}_{\mathrm{e}}$ while the much larger ice rumple \#14 generates a much smaller $\mathbf{F}_{\mathrm{e}}\left(12.4 \pm 4.4 \times 10^{12} \mathrm{~N}\right.$ vs. $1.1 \pm 1.6 \times$ $10^{12} \mathrm{~N}$, respectively). Both rumples are in relatively fastflowing areas of the ice shelf, and both are characterised by similar, low, $H_{a b}$. Including the point $(0,0)$, the equation for the best fit linear regression line is $\mathbf{F}_{\mathrm{e}}=2.97 \times 10^{6} \mathrm{~A}$ with $R^{2}=0.46(p<0.01, \alpha=0.05)$.

Dividing the effective resistance by the area of an ice rumple gives the apparent basal shear stress $\tau_{\mathrm{b}}$ (Fig. $5 \mathrm{~b}$ ). The magnitudes of $\tau_{\mathrm{b}}$ computed here are similar to values computed for ice stream sticky spots $\left(\tau_{\mathrm{b}}=20\right.$ to $\left.100+\mathrm{kPa}\right)$ (MacAyeal and others, 1995; Joughin and others, 2004). It is possible that the range of $\tau_{\mathrm{b}}$ values arises from the characteristics of the subglacial material (Bougamont and others, 2003; Iverson, 2010). Large rumples with relatively uniform surface elevation and smaller $\tau_{\mathrm{b}}$ may be underlain by softer sediments. Small features with large $\tau_{\mathrm{b}}$ may be grounded on bedrock rather than softer sediment. Differences in $\tau_{\mathrm{b}}$ across different ice stream outlet regions may reflect a 
a

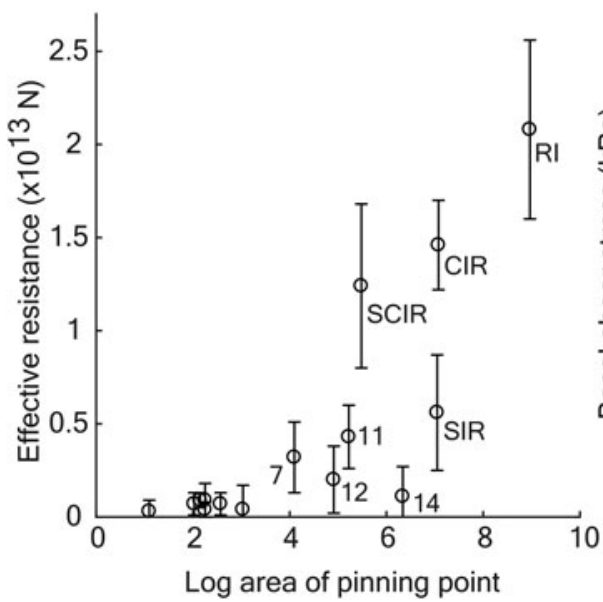

b

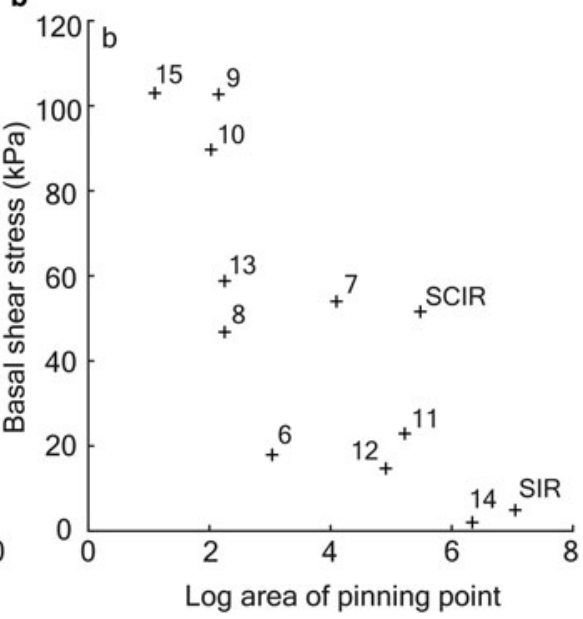

Fig. 5. Pinning point area vs. (a) effective resistance $\mathbf{F}_{\mathrm{e}}$ and (b) basal shear stress $\tau_{b}$.

difference in till geology and so, for example, we might surmise that the subglacial materials beneath the SCIR complex $\left(\tau_{\mathrm{b}}=51.6 \mathrm{kPa}\right)$ and ice rumple $\# 14\left(\tau_{\mathrm{b}}=2.0 \mathrm{kPa}\right)$ differ.

Our force budget results for CIR are in agreement with the original force budget analysis of MacAyeal and others (1987, 1989). While we calculate a smaller $\mathbf{F}_{\mathrm{e}}\left(1.4 \pm 0.2 \times 10^{13} \mathrm{~N}\right.$ vs. $2.26 \pm 0.07 \times 10^{13} \mathrm{~N}$ ), the oblique direction of the $\mathbf{F}_{\mathrm{e}}$ vector is almost identical to the direction of $\mathbf{F}_{\mathrm{e}}$ calculated by MacAyeal and others $(1987,1989)$. Our smaller $\mathbf{F}_{\mathrm{e}}$ can be attributed to changes in the flow field around CIR. Over the last four decades, the WIS ice plain has decelerated (Joughin and others, 2005; Winberry and others, 2014), potentially modifying the resistive effect of CIR on the grounding line. However, the higher data density in the present analysis, resulting in a finer spatial resolution of strain rates around CIR, may be partly responsible for the different magnitudes.

Bathymetric data for ocean cavities beneath ice shelves are often insufficient to resolve topographic rises beneath ice rises and rumples (e.g., Fürst and others, 2015; Berger and others, 2016). The Bedmap2 sub-shelf bathymetry does not resolve regions of elevated topography beneath the smallest ice rises and rumples examined here. Other features are sparsely sampled and seafloor elevation is interpolated over tens of kilometres. In particular, the bathymetry beneath the SCIR is represented by only four measurement points obtained by radio-echo sounding (Fretwell and others, 2013). Nevertheless, ice surface morphology indicates their presence and the force budget analysis conducted here indicates their importance. Failing to resolve the large $\mathbf{F}_{\mathrm{e}}$ generated by some relatively small features could have large consequences in an ice-sheet model (Favier and others, 2016; Reese and others, 2018).

\section{CONCLUSIONS}

Using a force budget approach, we quantified the magnitude and direction of drag forces generated by 15 pinning points and pinning point complexes within the RIS. Several of these features generate a large effective resistance and have far-ranging, regional effects (SCIR, RI, CIR, SIR). For other features (e.g., ice rumples $\# 7, \# 11, \# 12, \# 14$ ), the analysis indicates a small resistive effect upstream. The magnitude of the effective resistance does not necessarily depend on the area of the pinning point, the degree of groundedness (height above buoyancy), or the classification of the feature as an ice rise or rumple. Variations in the subglacial material also appear to play an important role in determining the effective resistance generated by each feature.

Pinning points that generate a large effective resistance (CIR, RI, SCIR) have clear upstream effects transverse to flow in addition to their direct upstream effects. Upstream, pinning points cause relative compression which slows the flow and thickens ice. Mass flux is redirected around each obstacle, causing thickening laterally. This may, as at CIR, result in a net effective resistance directed oblique to the flow direction across the grounding line. CIR thus buttresses the southern part of the WIS grounding line, the Mercer Ice Stream grounding line, and part of the Transantarctic Mountains coast. Mass flux redirection around the SCIR also generates regional thickening but here the resistive force is directed along flow.

Of all the RIS pinning points, the SCIR are remarkable for generating a large effective resistance despite a relatively small collective area and low degree of groundedness $\left(H_{a b} \sim 15 \mathrm{~m}\right)$. Net effective resistance generated by the SCIR is aligned in the upstream direction and the rumples, therefore, regulate the flow of MacIS and its grounding line. A band of large shear strain rates originating from the upstream edge of the SCIR separates the thicker and faster flow south of the SCIR from the region of reduced mass flux directly downstream from the SCIR. In other words, the SCIR also modify the force budget by creating an effective shear margin, which in turn modifies the thickness gradients across the eastern sector of the RIS. As the effective shear margin is associated with the diversion of mass flux from MaclS, ice is thicker than it would otherwise be downstream of BIS. This thicker ice is an indirect effect of the SCIR and generates additional flow buttressing. Even though the net effective resistance generated by the SCIR is directed upstream, additional mechanical effects extend their influence laterally.

The SCIR play a larger role in the RIS force budget than their morphology alone would suggest. Changes in the geometries of the crevasse trains downstream of the pinning points indicate that their surface morphology and/ or degree of groundedness has changed in the recent past. The average height above buoyancy for the SCIR is $\sim 15 \mathrm{~m}$ 
so only modest thinning is required for the ice shelf to detach from the sea floor. Feedbacks involving bed roughness, ice deformation and basal melt may also be important, given the inferred bed properties (hard bedrock rather than soft sediment) here. A natural progression of this work is to simulate ice shelf flow in the presence and absence of the SCIR.

\section{ACKNOWLEDGEMENTS}

This work was supported by the New Zealand Post Antarctic Scholarship and the New Zealand Antarctic Research Institute (NZARI) funded Aotearoa New Zealand Ross Ice Shelf Programme, 'Vulnerability of the Ross Ice Shelf in a Warming World'. We thank the editor and three reviewers for comments that helped us to improve the manuscript.

\section{REFERENCES}

Anderson JB and 10 others (2014) Ross Sea paleo-ice sheet drainage and deglacial history during and since the LGM. Quat. Sci. Rev., 100, 31-54 (doi: 10.1016/j.quascirev.2013.08.020)

Berger S, Favier L, Drews R, Derwael JJ and Pattyn F (2016) The control of an uncharted pinning point on the flow of an Antarctic ice shelf. J. Glaciol., 62(231), 37-45 (doi: 10.1017/ jog.2016.7)

Bindschadler RA and 5 others (1988) Ice-shelf flow at the boundary of Crary Ice Rise, Antarctica. Ann. Glaciol., 11, 8-13 (doi: 10.3189/S0260305500006248)

Bindschadler RA, Roberts EP and Iken A (1990) Age of Crary Ice Rise, Antarctica, determined from temperature-depth profiles. Ann. Glaciol., 14, 13-16 (doi: 10.3189/S0260305500008168)

Bindschadler R and 11 others (2011) Getting around Antarctica: new high-resolution mappings of the grounded and freely-floating boundaries of the Antarctic ice sheet created for the International Polar Year. Cryosphere, 5(3), 569-588 (doi: 10.5194/tc-5-569-2011)

Borstad CP, Rignot E, Mouginot J and Schodlok MP (2013) Creep deformation and buttressing capacity of damaged ice shelves: theory and application to Larsen C ice shelf. Cryosphere, 7(6), 1931-1947 (doi: 10.5194/tc-7-1931-2013)

Bougamont M, Tulaczyk S and Joughin I (2003) Numerical investigations of the slow-down of Whillans Ice Stream, West Antarctica: is it shutting down like Ice Stream C? Ann. Glaciol., 37, 239-246 (doi: 10.3189/172756403781815555)

Campbell AJ, Hulbe CL and Lee CK (2018) Ice stream slowdown will drive long-term thinning of the Ross Ice Shelf, with or without ocean warming. Geophys. Res. Lett., 45(1), 201-206 (doi: 10.1002/2017GL075794)

Clough JW and Hansen BL (1979) The Ross Ice Shelf project. Science, 203(4379), 433-434 (doi: 10.1126/science.203.4379. 433)

Conway $\mathrm{H}$, Hall BL, Denton GH, Gades AM and Waddington ED (1999) Past and future grounding-line retreat of the West Antarctic Ice Sheet. Science, 286(5438), 280-283 (doi: 10.1126/science.286.5438.280)

Crary AP (1961) Glaciological regime at Little America Station, Antarctica. J. Geophys. Res., 66(3), 871-878 (doi: 10.1029/ JZ066i003p00871)

Cuffey KM and Paterson WSB (2010) The physics of glaciers, 4th edn. Elsevier, Burlington, MA

DiMarzio JP (2007) GLAS/ICESat 500 m Laser Altimetry Digital Elevation Model of Antarctica, Version 1 (doi: 10.5067/ K2IMIOL24BRJ)

Dupont TK and Alley RB (2006) Role of small ice shelves in sea-level rise. Geophys. Res. Lett., 33(9), L09503 (doi: 10.1029/2005GL025665)
Engelhardt $\mathrm{H}$ (2004) Thermal regime and dynamics of the West Antarctic ice sheet. Ann. Glaciol., 39, 85-92 (doi: 10.3189/ 172756404781814203)

Fahnestock MA, Scambos TA, Bindschadler RA and Kvaran G (2000) A millennium of variable ice flow recorded by the Ross Ice Shelf, Antarctica. J. Glaciol., 46(155), 652-664 (doi: 10.3189/ 172756500781832693)

Fahnestock $M$ and 5 others (2016) Rapid large-area mapping of ice flow using Landsat 8. Remote Sens. Environ., 185, 84-94 (doi: 10.1016/j.rse.2015.11.023)

Favier L and Pattyn F (2015) Antarctic ice rise formation, evolution, and stability. Geophys. Res. Lett., 42(11), 4456-4463 (doi: 10.1002/2015GL064195)

Favier L, Gagliardini O, Durand G and Zwinger T (2012) A threedimensional full Stokes model of the grounding line dynamics: effect of a pinning point beneath the ice shelf. Cryosphere, 6 (1), 101-112 (doi: 10.5194/tc-6-101-2012)

Favier L, Pattyn F, Berger S and Drews R (2016) Dynamic influence of pinning points on marine ice-sheet stability: a numerical study in Dronning Maud Land, East Antarctica. Cryosphere, 10(6), 2623-2635 (doi: 10.5194/tc-10-2623-2016)

Fretwell P and 59 others (2013) Bedmap2: improved ice bed, surface and thickness datasets for Antarctica. Cryosphere, 7(1), 375-393 (doi: 10.5194/tc-7-375-2013)

Fried M, Hulbe C and Fahnestock M (2014) Grounding-line dynamics and margin lakes. Ann. Glaciol., 55(66), 87-96 (doi: 10.3189/ 2014AoG66A216)

Fürst JJ and 7 others (2015) Assimilation of Antarctic velocity observations provides evidence for uncharted pinning points. Cryosphere, 9(4), 1427-1443 (doi: 10.5194/tc-9-1427-2015)

Fürst JJ and 6 others (2016) The safety band of Antarctic ice shelves. Nat. Clim. Change, 6(5), 479-482 (doi: 10.1038/nclimate2912)

Goldberg D, Holland DM and Schoof C (2009) Grounding line movement and ice shelf buttressing in marine ice sheets. J. Geophys. Res., 114(F4), F04026 (doi: 10.1029/2008JF001227)

Griggs JA and Bamber JL (2009) Ice shelf thickness over Larsen C, Antarctica, derived from satellite altimetry. Geophys. Res. Lett., 36(19), L19501 (doi: 10.1029/2009GL039527)

Gudmundsson GH (2013) Ice-shelf buttressing and the stability of marine ice sheets. Cryosphere, 7(2), 647-655 (doi: 10.5194/tc7-647-2013)

Haran T, Bohlander J, Scambos T, Painter T and Fahnestock M (2014) MODIS Mosaic of Antarctica 2008-2009 (MOA2009) Image Map. (doi: 10.7265/N5KP8037).

Hudleston PJ (2015) Structures and fabrics in glacial ice: a review. J. Struct. Geol., 81, 1-27 (doi: 10.1016/J.JSG.2015.09.003)

Hulbe CL and Fahnestock M (2007) Century-scale discharge stagnation and reactivation of the Ross ice streams, West Antarctica. J. Geophys. Res., 112(F3), F03S27 (doi: 10.1029/2006JF000603)

Hulbe CL, Scambos TA, Lee CK, Bohlander J and Haran T (2013) Recent changes in the flow of the Ross Ice Shelf, West Antarctica. Earth Planet. Sci. Lett., 376, 54-62 (doi: 10.1016/J. EPSL.2013.06.013)

Iverson NR (2010) Shear resistance and continuity of subglacial till: hydrology rules. J. Glaciol., 56(200), 1104-1114 (doi: 10.3189/ 002214311796406220)

Jezek KC, Alley RB and Thomas RH (1985) Rheology of glacier ice. Science, 227(4692), 1335-1337 (doi: 10.1126/science.227. 4692.1335)

Joughin I, MacAyeal DR and Tulaczyk S (2004) Basal shear stress of the Ross ice streams from control method inversions. J. Geophys. Res., 109(B9), B09405 (doi: 10.1029/2003JB002960)

Joughin I and 10 others (2005) Continued deceleration of Whillans Ice Stream, West Antarctica. Geophys. Res. Lett., 32(22), L22501 (doi: 10.1029/2005GL024319)

Le Brocq AM, Payne AJ and Vieli A (2010) An improved Antarctic dataset for high resolution numerical ice sheet models (ALBMAP v1). Earth Syst. Sci. Data, 2(2), 247-260 (doi: 10.5194/essd-2-247-2010) 
MacAyeal DR, Bindschadler RA, Shabtaie S, Stephenson S and Bentley CR (1987) Force, mass, and energy budgets of the Crary Ice Rise complex, Antarctica. J. Glaciol., 33(114), 218230 (doi: 10.3189/S0022143000008728)

MacAyeal DR, Bindschadler RA, Stephenson S, Shabtaie S and Bentley CR (1989) Correction to: force, mass, and energy budgets of the Crary Ice Rise complex, Antarctica. J. Glaciol., 35(119), 151-152 (doi: 10.3189/s0022143000004901)

MacAyeal DR, Bindschadler RA and Scambos TA (1995) Basal friction of Ice Stream E, West Antarctica. J. Glaciol., 41(138), 247262 (doi: 10.3189/S0022143000016154)

MacAyeal DR, Rignot E and Hulbe CL (1998) Ice-shelf dynamics near the front of the Filchner-Ronne Ice Shelf, Antarctica, revealed by SAR interferometry: model/interferogram comparison. J. Glaciol., 44(147), 419-428 (doi: 10.3189/S0022143000002744)

Matsuoka K and 19 others (2015) Antarctic ice rises and rumples: their properties and significance for ice-sheet dynamics and evolution. Earth-Sci. Rev., 150, 724-745 (doi: 10.1016/j.earscirev. 2015.09.004)

Padman L, Erofeeva S and Joughin I (2003) Tides of the Ross Sea and Ross Ice Shelf cavity. Antarct. Sci., 15(1), 31-40 (doi: 10.1017/ S0954102003001032)

Pritchard HD and 5 others (2012) Antarctic ice-sheet loss driven by basal melting of ice shelves. Nature, 484(7395), 502-505 (doi: 10.1038/nature10968)

Reese R, Gudmundsson GH, Levermann A and Winkelmann R (2018) The far reach of ice-shelf thinning in Antarctica. Nat. Clim. Change, 8(1), 53-57 (doi: 10.1038/s41558-017-0020-x)

Rignot E, Mouginot J and Scheuchl B (2011a) Ice flow of the Antarctic Ice Sheet. Science, 333(6048), 1427-1430 (doi: 10.1126/science.1208336)

Rignot E, Mouginot J and Scheuchl B (2011b) MEaSUREs InSARBased Antarctica Ice Velocity Map (doi: 10.5067/measures/cryosphere/nsidc-0484.001).

Schodlok MP, Menemenlis D and Rignot EJ (2016) Ice shelf basal melt rates around Antarctica from simulations and observations. J. Geophys. Res.: Oceans, 121(2), 1085-1109 (doi: 10.1002/ 2015JC011117)

Taylor JR (1997) An introduction to error analysis: the study of uncertainties in physical measurements. University Science Books, New York, NY.

Thomas RH (1979) The Dynamics of Marine Ice Sheets. J. Glaciol., 24(90), 167-177 (doi: 10.3189/S0022143000014726)

van den Broeke M, van de Berg WJ and van Meijgaard E (2008) Firn depth correction along the Antarctic grounding line. Antarct. Sci., 20(5), 513-517 (doi: 10.1017/S095410200800148X)
Wen J and 5 others (2010) Basal melting and freezing under the Amery Ice Shelf, East Antarctica. J. Glaciol., 56(195), 81-90 (doi: 10.3189/002214310791190820)

Winberry JP, Anandakrishnan S, Alley RB, Wiens DA and Pratt MJ (2014) Tidal pacing, skipped slips and the slowdown of Whillans Ice Stream, Antarctica. J. Glaciol., 60(222), 795-807 (doi: 10.3189/2014JoG14J038)

\section{APPENDIX}

The integrals in the force budget analysis (Eqns (4, 6 and 9)) are computed as follows

$$
\begin{aligned}
& \mathbf{F}_{\mathrm{f}}=\sum_{j=1}^{N} \frac{1}{2} \Delta \lambda_{j} \hat{\mathbf{n}}_{j} \\
& \left\{\frac{1}{2} \rho_{i} g\left(H_{1}^{2}+H_{2}^{2}\right)+\frac{\alpha}{\beta} g\left(H_{1}+H_{2}\right)+\frac{\alpha}{\beta^{2}} g\left(2-e^{\beta H_{1}}-e^{\beta H_{2}}\right)\right\} \\
& \mathbf{F}_{\mathrm{d}}=-\sum_{j=1}^{N} \frac{1}{2} \Delta \lambda_{j}\left\{\left[2 \bar{v}_{1}^{z} H_{1}\left(\dot{\boldsymbol{\epsilon}}_{1} \cdot \hat{\mathbf{n}}_{j}+\left(\dot{\boldsymbol{\epsilon}}_{x x}+\dot{\boldsymbol{\epsilon}}_{y y}\right)_{1} \hat{\mathbf{n}}_{j}\right)\right]\right. \\
& \left.\quad+\left[2 \bar{v}_{2}^{z} H_{2}\left(\dot{\boldsymbol{\epsilon}}_{2} \cdot \hat{\mathbf{n}}_{j}+\left(\dot{\boldsymbol{\epsilon}}_{x x}+\dot{\boldsymbol{\epsilon}}_{y y}\right)_{2} \hat{\mathbf{n}}_{j}\right)\right]\right\}
\end{aligned}
$$

and

$$
\begin{aligned}
& \mathbf{F}_{\mathrm{w}}=\sum_{j=1}^{N} \frac{g \Delta \lambda_{j}}{2 \rho_{\mathrm{w}}} \hat{\mathbf{n}}_{j}\left[\frac{\rho_{i}^{2}}{3}\left(H_{2}^{2}+H_{1} H_{2}+H_{1}^{2}\right)\right. \\
& +\frac{2 \alpha \rho_{i}}{\beta\left(H_{2}-H_{1}\right)}\left(\frac{1}{2}\left(H_{2}^{2}-H_{1}^{2}\right)-e^{\beta H_{2}} \frac{\beta H_{2}-1}{\beta^{2}}+e^{\beta H_{1}} \frac{\beta H_{1}-1}{\beta^{2}}\right) \\
& \left.+\frac{\alpha^{2}}{\beta\left(H_{2}-H_{1}\right)}\left(H_{2}-H_{1}-\frac{2}{\beta} e^{\beta H_{2}}-\frac{2}{\beta} e^{\beta H_{1}}+\frac{1}{2 \beta} e^{2 \beta H_{2}}-\frac{1}{2 \beta} e^{2 \beta H_{1}}\right)\right] .
\end{aligned}
$$

A contour comprises $N$ segments with the subscript $j$ denoting the segment number. Subscripts 1 and 2 denote quantities at the start and endpoint of the jth segment, respectively. 